\title{
Quantitative risk management in gas injection project: a case study from Oman oil and gas industry
}

\author{
Mohammad Miftaur Rahman Khan Khadem ${ }^{1} \cdot$ Sujan Piya $^{1} \cdot$ Ahm Shamsuzzoha'
}

Received: 3 November 2016/Accepted: 15 September 2017/Published online: 22 September 2017

(C) The Author(s) 2017. This article is an open access publication

\begin{abstract}
The purpose of this research was to study the recognition, application and quantification of the risks associated in managing projects. In this research, the management of risks in an oil and gas project is studied and implemented within a case company in Oman. In this study, at first, the qualitative data related to risks in the project were identified through field visits and extensive interviews. These data were then translated into numerical values based on the expert's opinion. Further, the numerical data were used as an input to Monte Carlo simulation. RiskyProject Professional ${ }^{\mathrm{TM}}$ software was used to simulate the system based on the identified risks. The simulation result predicted a delay of about 2 years as a worse case with no chance of meeting the project's on stream date. Also, it has predicted $8 \%$ chance of exceeding the total estimated budget. The result of numerical analysis from the proposed model is validated by comparing it with the result of qualitative analysis, which was obtained through discussion with various project managers of company.
\end{abstract}

Keywords Risk analysis · Quantitative analysis · Project management $\cdot$ Monte Carlo simulation

Mohammad Miftaur Rahman Khan Khadem

khadem@squ.edu.om

1 Department of Mechanical and Industrial Engineering, Sultan Qaboos University, Al Khod, PO Box 33, 123 Muscat, Sultanate of Oman

\section{Introduction}

Risk can be defined depending on application domain (Wang et al. 2004). For example, in case of business domain risk is defined as the probability of successful outcomes. On the other hand, in project domain it is defined as the successful completion of a project within the predefined timeframe and cost (Ward and Chapman 2003; Perminova et al. 2008). According to Project Management Institute (PMI 1996), risk is defined as "an uncertain event or condition that, if it occurs, has a positive (opportunity) or negative (threat) impact on project objectives". Since projects are subjected to uncertainties either due to external or internal factors, risk management is needed to reduce the probability of occurrence and/or the negative impact of risky events (Fan et al. 2008). In terms of uncertainties, risks are categorized from low, medium, and high, depending on the overall impact of risks. Tah and Carr (2001) described risks based on a hierarchical risk breakdown structure, where generic risks and remedial actions can be stored in catalogues. From a quantitative point of view, risk is treated using countermeasures to reduce either the likelihood or consequence of a risk or defer the risk to some third party (e.g. insurance). In order to implement a countermeasure of risk there must be a balance against associated cost and the expected utility of implementing the measure (Aggarwal and Ganeshan 2007; Vose 2008). There might also be a possibility that countermeasures of risks can expose additional risks or retail residual risk that need to be considered as well (Trkman and McCormack 2009). This process should improve risk sensitivity and awareness.

Risk management in an industrial establishment is a systematic process that is executed according to manufacturer's own policies and best practices. The process has a major role in understanding the cause-effect relations 
between risks and their accompanied operations (Miller 1990; Narasimhan and Talluri 2009; Balasubramanian et al. 2011). It can be both pro-active, where probability of occurrence is lowered by some managerial procedures, and reactive that reacts immediately by the management procedures aiming to minimize negative impact after the risk has occurred. The occurrence of a risk usually changes over time due to which monitoring activity of risk needs to be realized (Raz and Michael 2001; Patterson and Neailey 2002). The management of risk includes the total process of identifying, controlling and minimizing the impact of uneven or uncertain events. According to Westney (2001), basically, risk management process involves four different phases such as Risk identification, Risk assessment, Risk analysis and Risk mitigation. In the risk identification phase, the risks that may affect the project objectives are identified and their characteristics are determined. The impact of the identified risks is determined during the risk assessment phase. In the risk analysis phase, risk is analyzed by estimating the likelihood of the event occurring and the consequence of the event if it occurs. The last phase is risk mitigation phase and it starts by reviewing the results of the risk analysis to determine the highest priority risks for mitigation. However, most of the researchers on risk management have focused on risk identification and analysis phase (Kirkire et al. 2015).

Out of the four different phases as discussed above, risk analysis phase is of prime importance. The objective of risk analysis phase is to prioritize the identified risks and to provide data to assist in the evaluation and treatment of risks. In risk analysis process, there is a need of systematic use of available information to determine how often specified events may occur and the magnitude of their consequences (Ramos and Veiga 2011; Smith 2009). This process can be both qualitative, semi-qualitative, quantitative or combination of any three. Qualitative risk analysis generally involves assessing a situation by instinct. On the other hand, quantitative risk analysis attempts to assign numeric values of risks, either by using empirical data or by quantifying qualitative assessments (Palisade 2016). Risk analysis method that is based on systems and probability are generally designed for cases in which sufficient failure statistics are unavailable (Selvik and Aven 2011; Mahmood et al. 2011).

This research is motivated by the fact that currently the common methods applied in organizations to analyze risks are mostly deterministic or qualitative, which are overly simplified, or inconsistent in application and assumption. Such inconsistency makes them unreliable or impractical. It is a universal fact that there is no project without uncertain events. Under uncertainty, we are confronted with the lack of data and information such that deterministic approach cannot truly calculate the risk involved
(Khalaj et al. 2013). Also, it has been observed that many organizations refrain from applying quantitative risk analysis method due to the lack of knowledge of using it and the benefits such an analysis can add to their projects. Moreover, it has been observed that in many projects, project schedule and cost estimation are treated as separate, isolated system. Therefore, there is a need for comprehensive and reliable stochastic quantitative risk analysis method that can be applied in projects to analyze risks and manage them. Applying such method will enable project managers in the real world to make decisions in a more effective and efficient way. Therefore, this research study identified three research questions that are answered during the execution of this research.

- Research question 1: What risk factors impact project the most and why?

- Research question 2: How the risks and uncertainty can be quantified and managed in project planning?

- Research question 3: How simulation model can help in quantifying and managing risk in a project environment?

The remaining portion of the paper is structured as follows: "Literature review" reviews the research that has been carried out in this area in the past. "Research methodology" discusses the methodology that has been followed in the execution of this research work. "Risk management: perspective from quantitative risk analysis" discusses the risk management from the perspective of quantitative risk analysis. "A case study" is dedicated to the case study. "Managerial implications" highlights the managerial insights drawn from the research. The paper concludes with future research directions in "Conclusions and recommendations".

\section{Literature review}

The success and failure of project mostly depends on the perceptions of its stakeholders (Bourne and Walker 2008). Project manager needs to manage both the expectations and perceptions of its stakeholders within the capacities and capabilities. Success in project is an ambiguous, inclusive and multidimensional concept and its performance is measured to a specific context (Ika et al. 2010). Due to globalized project environment, there are increasing concerns to managing associated risks in order to fulfill project objectives (Artto et al. 2008). There still lacks addressing of risks arising from organizations involved in project networks (Chapman and Ward 2002, 2003; Ward and Chapman 2003).

In project management context, risk is organized at the highest level of management, with a global vision (Suslick 
and Schiozer 2004; Aven and Vinnem 2005). It is often scaled as positive (business opportunities) or negative (operational hazards or threats) and can be external risks (customers' demands, market competition, suppliers, government actions, environmental protections, etc.) and internal risks (products, resources, processes, new technology, etc.). Different approaches are often considered by the manufacturers to mitigate probable risk such as identification, scaling, ranking and prioritization. These mitigation plans are stored in the knowledge base that is made available for future use (Miller and Waller 2003).

With respect to project-based risk management perspective, it is important to quantifying associated risks in terms of their detrimental effects on projects performances. This quantification allows defining the possibility of deviation in the results from the expected goals. It also helps managers to estimate quantitatively the potential risk level of a project before necessary resources are allocated. In order to quantify the risk, it is necessary to collect assessment information to build a risk estimation model for project-based business. The manager has to make significant effort to align risk with the organizational strategic decision in order to steer the project. At the same time, risks that are confronted during the course of the project can be managed most expeditiously with clear top management commitment. In order to have successful risk management effort in projects, upper management must communicate to the affected project units, motivate movement and step in to resolve differences that caused risks.

It is critical to manage the multifaceted risks in any kinds of projects in order not only to be secured but also to make profit. Several risk management frameworks in projects are available. Miller (1992) presented a framework for categorizing the uncertainties as are faced by the companies and highlights risk management responses from both financial and strategic point of views. Zhang et al. (2010) proposed an information risk management framework for better understanding within the business domain of cloud computing. This framework supports identifying a threat in cloud computing environment and to identifying vulnerability. Wang et al. (2010) proposed a new risk management framework that aligns project risk management with respect to research and development and performance measurement perspectives. A balanced scorecard method is used to identify the risks and performance measures within R\&D based organizations. Various risk management frameworks and their outcomes can be summarized as in Table 1 below.

From the literature review, it is noticed that extensive works have been done to managing risk in project business; however, little researches are done on quantifying risks associated in managing projects. From this literature review, it is also revealed that quantification of risk factors is not widely used due to lack of knowledge and requirement of extensive effort. This research gap is explored within the scope of this research, wherein identification, analysis, quantification and management of identified risks in oil and gas industry project are highlighted through Monte Carlo simulation and RiskyProject Professional $^{\mathrm{TM}}$ software.

\section{Research methodology}

According to Pinsonneault and Kraemer (1993), survey method is appropriate if the research has to answer the questions about what and how. Therefore, in this research, we use a survey method as a research instrument. Extensive field visits to oil and gas companies have been carried out to collect information's that are pertinent to the scope of this research. However, before the field visits, extensive literature reviews were carried out to understand risk management procedure. It covers review of literatures on risks management in general, as well as, risk management in a specific industries ranging from construction project to IT industry. During the field visit, one-to-one interviews with the participants as well as group discussions were carried out to understand the system or project under consideration and the risks associated with it. Here, it should be noted that the risks are either related to the deadline or to the cost which constitutes two major concerns related to any project. The field visit has been carried out in an oil and gas industry that exists in Oman and the participants in the survey vary from project managers and other engineers working in the project. Table 2 below shows the number of participants and their designation.

Survey helps to identify the associated risks and the extent to which it will impact the project. The qualitative information obtained through survey was further translated into quantitative data based on expert's opinion. For the purpose, a number of brainstorming sessions with the experts were conducted. Monte Carlo simulation is used in this research as a quantitative risks analysis technique. These quantitative data, in the form of probability, were fed as an input to Monte Carlo simulation to simulate the system. RiskyProject Professional ${ }^{\mathrm{TM}}$ software was used as a platform for the simulation and to get the output for the system analysis.

\section{Risk management: perspective from quantitative risk analysis}

The traditional approach in risk analysis was to break down the problem or the risk into smaller simplified components and analyze them in relative isolation. However, this approach does n't effectively represent the real life 
Table 1 Various risk management frameworks with their contributions

\begin{tabular}{|c|c|c|c|}
\hline $\begin{array}{l}\text { Serial } \\
\text { no. }\end{array}$ & $\begin{array}{l}\text { Contributing } \\
\text { author(s) }\end{array}$ & Framework type & Fundamental contributions \\
\hline 1. & Jaafari (2001) & $\begin{array}{l}\text { Risk analysis to strategy- } \\
\text { based project management }\end{array}$ & $\begin{array}{l}\text { It is mentioned that risks evaluation should be based not only on delivering } \\
\text { projects but also on crafting, developing and operating }\end{array}$ \\
\hline 2. & $\begin{array}{l}\text { Trkman and } \\
\text { McCormack } \\
(2009)\end{array}$ & $\begin{array}{l}\text { Supply chain risk } \\
\text { management }\end{array}$ & $\begin{array}{l}\text { It indicated that supply chain risk can be mitigated based on suppliers } \\
\text { characteristics, performances and the business environment }\end{array}$ \\
\hline 3. & Pettit et al. (2010) & Supply chain resilience & $\begin{array}{l}\text { This research suggested that supply chain resilience can be assessed with respect } \\
\text { to vulnerabilities and capabilities of firms }\end{array}$ \\
\hline 4. & $\begin{array}{l}\text { Giannkis and Louis } \\
\text { (2011) }\end{array}$ & $\begin{array}{l}\text { Multi-agent based supply } \\
\text { chain risk management }\end{array}$ & $\begin{array}{l}\text { It proposed a multi-agent based decision support system for managing } \\
\text { disruptions and risks in manufacturing supply chain }\end{array}$ \\
\hline 5. & $\begin{array}{l}\text { Bosch-Rekveldt } \\
\text { et al. (2011) }\end{array}$ & $\begin{array}{l}\text { Characterizing project } \\
\text { complexity }\end{array}$ & $\begin{array}{l}\text { It is recommended that complexity of projects can be managed through assessing } \\
\text { the front-end complexity of engineering projects }\end{array}$ \\
\hline 6. & $\begin{array}{l}\text { Alhawari et al. } \\
\text { (2012) }\end{array}$ & $\begin{array}{l}\text { Knowledge-based risk } \\
\text { management }\end{array}$ & $\begin{array}{l}\text { It contributed by providing a method for employing knowledge-based risk } \\
\text { management to keep organizations competitive within business environment }\end{array}$ \\
\hline 7. & $\begin{array}{l}\text { Marcelino-Sadaba } \\
\text { et al. (2014) }\end{array}$ & $\begin{array}{l}\text { Methodology for project risk } \\
\text { management }\end{array}$ & $\begin{array}{l}\text { A risk management method is outlined based on project risk management } \\
\text { including simple tools, templates and risk checklists }\end{array}$ \\
\hline 8. & Yildiz et al. (2014) & $\begin{array}{l}\text { Knowledge-based risk } \\
\text { mapping }\end{array}$ & $\begin{array}{l}\text { A knowledge-based risk mapping tool is presented for systematically assessing } \\
\text { risks in global construction projects }\end{array}$ \\
\hline 9. & $\begin{array}{l}\text { Aqlan and Lam } \\
\text { (2015) }\end{array}$ & $\begin{array}{l}\text { Fuzzy-based supply chain } \\
\text { risk assessment }\end{array}$ & $\begin{array}{l}\text { It presented a framework to identify risks based on experts knowledge, historical } \\
\text { data and supply chain structure }\end{array}$ \\
\hline 10 & $\begin{array}{l}\text { Javani and } \\
\text { Rwelamila (2016) }\end{array}$ & $\begin{array}{l}\text { Risk management in IT } \\
\text { projects }\end{array}$ & $\begin{array}{l}\text { This research emphasized on managing risk as a knowledge base and developing } \\
\text { a formal and systematic approach to mitigate risks }\end{array}$ \\
\hline 11. & $\begin{array}{l}\text { Giannakis and } \\
\text { Papadopoulos } \\
\text { (2016) }\end{array}$ & $\begin{array}{l}\text { Risk management for supply } \\
\text { chain sustainability }\end{array}$ & $\begin{array}{l}\text { This research highlights an operational perspective of supply chain sustainability } \\
\text { through considering a risk management process in an integrated way }\end{array}$ \\
\hline
\end{tabular}

Table 2 Participants in the interview and group discussion

\begin{tabular}{lll}
\hline Serial no. & Designation & Number \\
\hline 1 & Project managers & 2 \\
2 & Planning engineer & 1 \\
3 & Rotating equipment engineer & 1 \\
4 & Process engineer & 2 \\
5 & Mechanical engineer & 1 \\
6 & Safety engineer & 2 \\
7 & Pipeline engineer & 1 \\
8 & Operation engineer & 1 \\
\hline
\end{tabular}

interactions (Lewis et al. 2004). Komlosi (2001) briefly described the development of risk analysis techniques in oil and gas industry. These methods were started to be very basic and simple like the $1 / 3$ rule. Later, deterministic approaches and various indices like profitability index and internal rate of return were introduced to the decision making process. However, there was a need for a technique that will look into uncertainties. At the beginning the models were developed by increasing or decreasing a key parameter by a certain percentage and see the impact on the outcome. Unfortunately, such an approach usually fails to effectively model realistic scenario. This warrants the need for a stochastic method to manage various input parameters as probability variables. According to Kirchsteiger (1999) probabilistic approach has many advantages over the deterministic approach.

A number of tools have been used to run stochastic risk analysis such as Bayesian theory, Monte Carlo analysis, fuzzy set theory and four moments methods (Jouandou 2009). Monte Carlo simulation is considered as one of the most recommended quantitative risk analysis techniques for analyzing cost and schedule risks (Lewis 2010).

\section{Monte Carlo simulation}

Monte Carlo simulation performs risk analysis by building models of possible results by substituting a range of values-a probability distribution-for any factor that has inherent uncertainty. It then calculates results over and over, each time using a different set of random values from the probability functions. Depending upon the number of uncertainties and the ranges specified for them, a Monte Carlo simulation could involve thousands or tens of thousands of recalculations before it produces distributions of possible outcome values (Chou 2011). 
The use of Monte Carlo simulation provides number of advantages over the use of deterministic analysis and the other probabilistic tools such asthe following:

- The outcomes specify which event could happen and its probability of occurrence.

- Easy to represent the data in graphical form.

- Easy to run sensitivity analysis and determine which variable has the significant impact on the outcome.

- Allows modeling the dependency between input variables.

- Predicts the degree of project success.

Therefore, Monte Carlo simulation has been selected as a tool to perform risk analysis on project cost and schedule in this research through a case study.

\section{Project cost risk analysis}

In cost risk analysis, the likelihood of cost deviation against estimates is determined. Some of the reasons for deviation are as follows:

- The estimate is unrealistic and low.

- A management decision to reduce bid price.

- Uncontrolled increase in scope of work.

- Unforeseen technical difficulties and schedule delays.

The cost risk analysis is done by using cost estimation model, which starts with breaking down cost items into a manageable level, usually in break down structure. Probability distribution is then estimated for each cost item to accommodate uncertainty. Finally, the distributions are combined to determine the probability distribution for the total cost.

\section{Project schedule risk analysis}

In schedule risk analysis, the likelihood of missing the deadline against estimates is determined. The risks in project schedule can be due to the following reasons:

- Project is complex and involves many different parties (contractors, suppliers and so on).

- Inadequate knowledge of the work to be performed resulting in optimistic schedule.

- Lack of adequate float or management reserve.

- Uncontrolled increase in scope of work.

Similar to the cost estimate model, the probability distribution for each schedule item is determined. The output of the model is a cumulative distribution that estimates the expected duration of the project and the likelihood of exceeding certain schedule length.

\section{A case study}

\section{Background}

As a source of non-renewable energy, oil and gas are considered as extremely valuable resources for many countries whose economy rely mainly on petroleum (Esmaeili et al. 2015). The selected case study is for a gas injection project carried out by an oil and gas company in one of the oil fields in the Sultanate of Oman. Basically, production rate of oil from oil well will be at its peak in the beginning of the production cycle. However, slowly the production rate will start diminishing. At that instance, to enhance oil recovery from oil and natural gas wells, secondary production methods were employed. Gas injection is one of those methods and is widely used in oil and gas industry.

The project's nature is risky as it involves processing very toxic fluids at high pressure. In addition of being toxic, the gas is highly corrosive. This toxicity and corrosiveness is due to the high concentrations of $\mathrm{H}_{2} \mathrm{~S}$ and $\mathrm{CO}_{2}$. In addition to the highly risky nature of the processed fluid, the proposed facilities are to be constructed in brown field, i.e. to be installed within the existing facility adding complexity to the construction activity. The scope of the gas injection project includes installing the following units:

- Gas dehydration unit through the use of Tri-Ethylene Glycol (TEG). The unit will dehydrate injection gas to reduce the water content and hence minimize the use of corrosion resistance alloys (CRA) as material of construction.

- High-pressure injection compressor to boost the dehydrated gas pressure to the required injection pressure set by the reservoir engineers.

- High-pressure transport system consisting of highpressure pipeline transferring injected gas from the compressor discharge to the injection wellhead.

- Gas injection wells.

- Piping modification within the existing facility.

- Providing the required utilities.

\section{Risk analysis model}

Figure 1 presents the flow chart of the process followed in this study in an attempt to manage risk within the project. From Fig. 1, it is seen that the process flow chart consists of four components, namely company input, model construction, running simulation and then results. Details of the flow chart are explained below. 
Fig. 1 Process flowchart

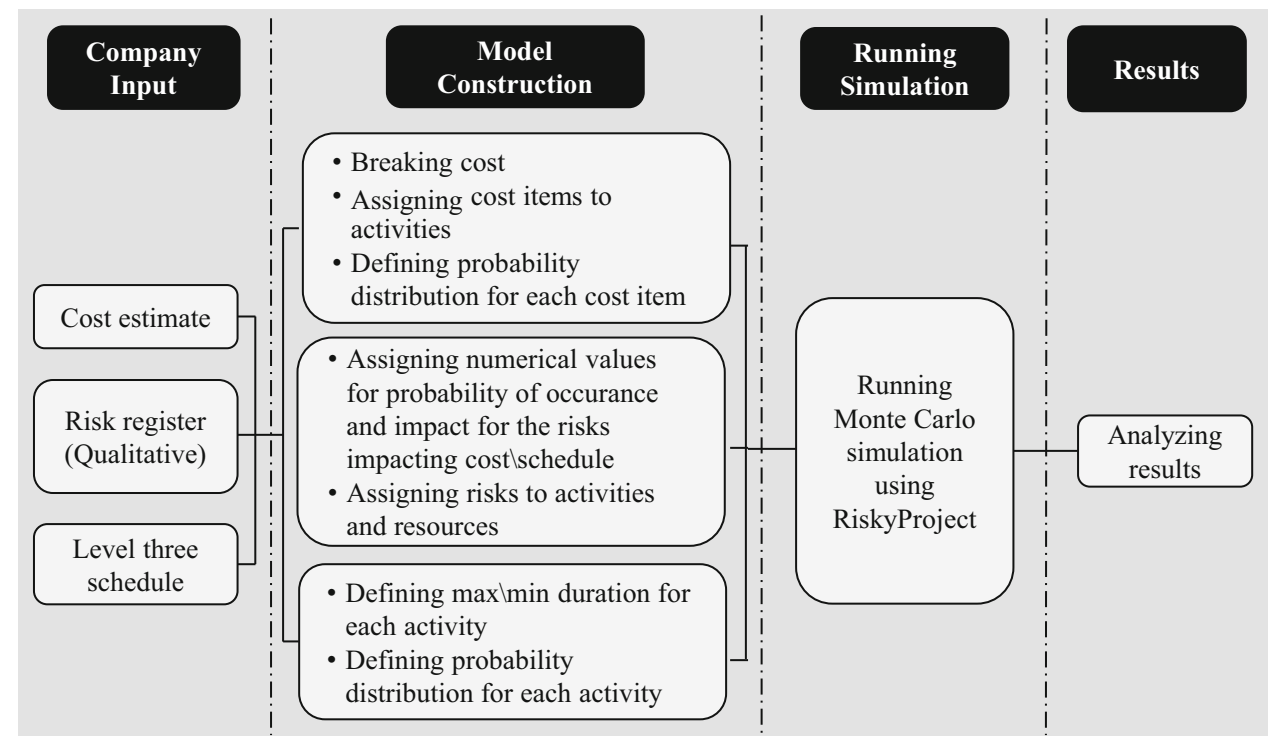

\section{Company input}

\section{Cost estimate}

The project cost estimate was developed by the company cost-engineering department based on the company database. The project's cost estimate includes base cost, contingency cost, cost to cushion the effect of future market condition and escalation. Table 3 summarizes the main items in the cost estimate:

\section{Project schedule}

The project team's planning engineer with the input from the project engineer has prepared the project's schedule. At this stage of the project, level 4 schedule has been prepared. However, for the objective of this study, level 3 has been used as level 4 is very detailed and covers over 1700 activity.

\section{Risk register}

Basically, risk register consists of brief description about the risks associated with the project, its likelihood and

Table 3 Project's cost estimation

\begin{tabular}{ll}
\hline Item description & Cost, million USD \\
\hline Bases estimate & 99.7 \\
Future market condition & 3.70 \\
Contingency & 13.37 \\
Escalation & 4.25 \\
Total & $\mathbf{1 2 1 . 0 2}$ \\
\hline
\end{tabular}

impact on the project. Risk register may be qualitative or it may be quantitative. Qualitative risk register is the one where the likelihood of occurrence of risk are estimated by ranking them as "high" to "low". On the other hand, if the likelihood of occurrence is put in the form of probabilistic number then it is known as quantitative risk register. In this research both qualitative as well as quantitative analysis has been carried out. Risk register starts with the identification of risk.

\section{Risk identification}

The risks involved in the project under consideration were identified through field visit, interview with the workers and consultation with site engineers. Also, project team was requested to brainstorm all the potential risk factors. Following 16 factors were identified as the risks involved in this project that leads to cost overrun or delay in the schedule or both of them.

1. Working adjacent to existing live plant leading to exposure to high $\mathrm{H}_{2} \mathrm{~S}$ gas The high $\mathrm{H}_{2} \mathrm{~S}$ content in the processed gas adds complexity to the construction activities, as it requires limiting the capacity of the construction crew, trained crew with safety procedures and longer shutdown durations. In addition to the delay, fatality may occur due to $\mathrm{H}_{2} \mathrm{~S}$ exposure.

2. Lack of installation and commissioning spares leads to delay in start-up In many instances, ordering spares parts is overlooked or due to transport/storage, they are lost resulting in delays.

3. Footprint specified in the plot plan is not met by the package Vendors resulting in delay in Engineering Sometimes there is a mismatch between footprint area specified by the equipment vendor and between what 
has been considered by the engineering consultant. This would result in re-work of some of the engineering activities and hence delay in the preceding activities.

4. Pipe and pipe fittings of 10,000\#: Sourcing from mill and expected delay due to small quantity The highpressure rating pipes are to be installed downstream the injection compressor up to the injection wellhead. Since the quantity to be ordered is relatively small, the order is expected not to be very attractive to the manufacturer and hence delay is likely to occur.

5. Complex interfaces within package vendors leading to delay in delivery of vendor packages resulting in project delay The project has number of interfaces, which have to be managed. The risk arises due to having different parties working in their scopes in isolation and leaving the interfaces with poor definition. For example, any changes within the TEG unit will affect the quality of the dehydrated gas and hence the design of the injection compressor.

6. Failure of Vendors to comply with approved designs resulting in delay Sometimes the vendor will propose materials which are not approved by the project.

7. Failure during acceptance testing resulting in delays Vendors have to prove that their equipment delivers the approved design by testing it at factory and site conditions. Failures can be minor or severe and will end up in delaying the project.

8. Construction contractor inexperience of CRA, material leading to delay and rework High-pressure rating and corrosion resistance alloy (CRA) materials are not widely used in the company and the contractor may not be familiar in construction using this type of materials.

9. Late arrival of materials on site due to poor vendor performance or quality failures The failure of vendor in delivering materials as per the agreed schedule and the quality thereby delaying construction activities and hence the overall on stream date.

10. Late provision of vendor data resulting in a delay of the Approved for Construction $(A F C)$ package Without vendor data, the engineering contractor cannot furnish the design leading in delay in delivering the AFC.

11. Late placement of the purchase orders If there is delay in placing the purchase order (PO) this will result in delaying the startup of construction activities.

12. Market price rise leading to an increase in CAPEX This is a global risk which will significantly affect the cost of all the items.

13. Lack of Sour experience of E\&P contractor leading to rework The design specifications for sour facilities are quite stringent compared to sweet service and were developed recently. So the engineering contractor may not be familiar with these specifications.
14. Lack of adequate operations staff to support construction, commissioning and start-up There is no dedicated operation staff for this project and it is shared with other fields.

15. Unauthorized deviation from vendor leading to rework or schedule delay Vendors have to design their equipment as per the project-developed philosophies and company design specifications.

16. Construction productivity is poor due to concurrent operations and $\mathrm{H}_{2} \mathrm{~S}$ safety measures This is similar to risk No. 1 with the difference that the delay due to this risk is solely driven by the safety measures and not by fatality occurrence.

Next, to rank and evaluate the identified risks, qualitative comparison was done using risk assessment matrix as shown in Table 4. The ranking ended up by defining risk as high-, medium- or low-level risk. This is achieved by understanding the impact of risk and then through the experiences of the project team of how likely that risk occur. The intersection of consequence and likelihood from Table 4 would define risk as high, medium and low. It should be noted that the 16 risks that have been identified involve consequences only to the people or assets.

To use the result of risk assessment matrix for further analysis, it is necessary to convert qualitative description on risk into quantitative value, which will be an input to the simulation model. Such conversion, in the form of probability, is carried out by seeking expert opinion. These probabilities were used in building the stochastic model. Table 5 lists the risk factors with their consequences, likelihood, level of risks and associated probability. These numerical values for probabilities were collected from the project's team engineers through a brainstorming discussion. The team consisted of two project engineers, one rotating equipment engineer and one planning engineer. For those risks where there was debate on their values, an average value was considered. These risks have been identified as possible sources of causing either project overrun or delays.

\section{Model construction}

The model as displayed in Fig. 1 is constructed using software called RiskyProject Professional ${ }^{\mathrm{TM}}$ which is a project risk management tool provided by Intaver Institute. During model construction, the costs were broken down and assigned to activity levels, which were then defined by specific probability distribution. In addition, in the model, the probability and occurrence of risks were defined to activities and resources and then assigned by numerical values. Finally, the maximum and minimum durations on the activities were defined in the model, which were 
Table 4 Risk assessment matrix

\begin{tabular}{|c|c|c|c|c|c|c|c|}
\hline \multicolumn{8}{|c|}{ Matrix used for risk assessment } \\
\hline \multirow{3}{*}{$\begin{array}{l}\text { పे } \\
\text { పे } \\
\text { ప }\end{array}$} & \multicolumn{2}{|c|}{ Consequences } & \multicolumn{5}{|c|}{ Likelihood of risk level } \\
\hline & People & Assets & $\mathrm{A}$ & $\mathrm{B}$ & $\mathrm{C}$ & $\mathrm{D}$ & $\mathrm{E}$ \\
\hline & $(\mathrm{P})$ & $(\mathrm{S})$ & $\begin{array}{l}\text { Never } \\
\text { heard of } \\
\text { in the } \\
\text { industry }\end{array}$ & $\begin{array}{l}\text { Heard of } \\
\text { in the } \\
\text { industry }\end{array}$ & $\begin{array}{l}\text { Has happened } \\
\text { in our } \\
\text { organization or } \\
\text { more than once } \\
\text { per year in the } \\
\text { industry }\end{array}$ & $\begin{array}{l}\text { Has happened } \\
\text { at the location } \\
\text { or more than } \\
\text { once per year } \\
\text { in our } \\
\text { organization }\end{array}$ & $\begin{array}{c}\text { Has } \\
\text { happened } \\
\text { more than } \\
\text { once per } \\
\text { year at the } \\
\text { location }\end{array}$ \\
\hline 0 & No injury or health effect & $\begin{array}{c}\text { No } \\
\text { damage }\end{array}$ & & & & & \\
\hline 1 & $\begin{array}{c}\text { Slight injury or health } \\
\text { effect }\end{array}$ & $\begin{array}{c}\text { Slight } \\
\text { damage }\end{array}$ & & & & & \\
\hline 2 & $\begin{array}{l}\text { Minor injury or health } \\
\text { effect }\end{array}$ & $\begin{array}{c}\text { Minor } \\
\text { damage }\end{array}$ & & & & & \\
\hline 3 & $\begin{array}{l}\text { Major injury or health } \\
\text { effect }\end{array}$ & $\begin{array}{c}\text { Moderate } \\
\text { effect }\end{array}$ & & & & & \\
\hline 4 & $\begin{array}{l}\text { Permanent total disability } \\
\text { or up to } 3 \text { fatalities }\end{array}$ & $\begin{array}{l}\text { Major } \\
\text { effect }\end{array}$ & & & & & \\
\hline 5 & More than 3 fatalities & $\begin{array}{c}\text { Massive } \\
\text { effect }\end{array}$ & & & & & \\
\hline
\end{tabular}

collected through brainstorming sessions with engineers from various discipline related to the project. The maximum and minimum values for the cost items were not available. Since the overall cost estimation is within -10 to $15 \%$ accuracy from historical data, the individual cost items were provided with the same range for fixed cost items too due to the market uncertainties. Also, the following assumptions were considered in constructing the model:

- According to PMI standard (1996) triangular distribution is selected for activities and costs.
- The calendar is based on 10 working hours per day and 5 working days per week.

- The cost per man-hour was derived from the total cost estimate and the estimate of man-hour for detailed design.

- Links between activities are maintained as per MS original Project plan. The most common link used to define relation between activities is Finish to Start (FS).

Each of the identified risk has been assigned to certain activity and/or resource, i.e., the impact of that risk can lead to delay of that assigned activity or increase of cost in

Table 5 Selected risk factors with their probabilities

\begin{tabular}{|c|c|c|c|c|c|}
\hline No. & Risk & Severity/consequence & Likelihood & $\begin{array}{l}\text { Risk } \\
\text { level }\end{array}$ & $\begin{array}{l}\text { Probability, } \\
\%\end{array}$ \\
\hline 1 & Working adjacent to existing live plant leading to exposure to high $\mathrm{H}_{2} \mathrm{~S}$ gas & $5(\mathrm{P})$ & $\mathrm{C}$ & High & 40 \\
\hline 2 & Lack of installation and commissioning spares & $3(\mathrm{~S})$ & $\mathrm{E}$ & High & 90 \\
\hline 3 & Footprint specified in the plot plan is not met by the package vendors & $2(\mathrm{~S})$ & $\mathrm{E}$ & Medium & 90 \\
\hline 4 & Delay in receiving pipe and pipe fittings & $4(\mathrm{~S})$ & $\mathrm{E}$ & High & 90 \\
\hline 5 & $\begin{array}{l}\text { Complex interfaces within package vendors (compressor vendors, TEG } \\
\text { vendors, sub vendors and E\&P contractor) }\end{array}$ & $4(\mathrm{~S})$ & $\mathrm{D}$ & High & 70 \\
\hline 6 & $\begin{array}{l}\text { Failure of vendors to comply with approved designs resulting in re-design/ } \\
\text { re-work }\end{array}$ & $4(\mathrm{~S})$ & $\mathrm{C}$ & Medium & 50 \\
\hline 7 & Failure during acceptance testing & $3(\mathrm{~S})$ & $\mathrm{E}$ & High & 70 \\
\hline 8 & Inexperience of construction contractor on CRA material & $5(\mathrm{~S})$ & $\mathrm{E}$ & High & 90 \\
\hline 9 & Poor vendor performance or quality failures & $4(\mathrm{~S})$ & $\mathrm{D}$ & High & 70 \\
\hline 10 & Late provision of vendor data & $4(\mathrm{~S})$ & $\mathrm{D}$ & High & 70 \\
\hline 11 & Late placement of the purchase orders $(\mathrm{PO})$ & $4(\mathrm{~S})$ & $\mathrm{C}$ & Medium & 95 \\
\hline 12 & Market price rise & $4(\mathrm{~S})$ & $\mathrm{D}$ & High & 70 \\
\hline 13 & Lack of sound experience of E\&P contractor & $4(\mathrm{~S})$ & $\mathrm{D}$ & High & 70 \\
\hline 14 & Lack of adequate operations staff & $4(\mathrm{~S})$ & $\mathrm{D}$ & High & 70 \\
\hline 15 & Unauthorized deviation from vendor & $3(\mathrm{~S})$ & $\mathrm{E}$ & High & 85 \\
\hline 16 & $\begin{array}{l}\text { Construction productivity is poor due to concurrent operations and } \mathrm{H}_{2} \mathrm{~S} \\
\text { safety measures }\end{array}$ & $4(\mathrm{~S})$ & $\mathrm{D}$ & High & 70 \\
\hline
\end{tabular}


the assigned resource or influence both. While entering the data in the risk register, the following assumptions have been considered:

- The impact/probability of the same risk factor is not necessarily the same for activity and resource.

- For a risk factor linked to a number of activities, probability has been broken down to the various activities as advised by the software support.

- No correlations between risks have been considered.

- Correlations between risks and schedule/cost have been considered by linking the risk impact to activities and cost items.

\section{Running simulation}

\section{Model validation}

The result obtained from the model is as shown in Table 6 . This result was validated by crosschecking it with the results obtained from the qualitative analysis. In the table, risks are arranged according to their ranking. This ranking comes from the output of the simulation model associated with the risk. As shown in Table 6, it was found that all the risks which have been ranked as high-risk factors are already classified by the project team for being at high risk (except for the risk of late placement of PO). Late placement of PO was classified at medium risk level. However, at the time this assessment has been carried out, the probability of this risk occurring has increased significantly.

In addition to this, the results were discussed and shared with the project team. The project engineers have highlighted that with respect to the project's duration, they anticipate a delay of at least 1 year and cost overrun of not less than $10 \%$ over the total estimated cost.

\section{Results and analysis}

\section{Project cost}

The results from the model runs related to the costs are summarized in Table 7. The base cost provided in the company cost estimate (Table 3) is $\$ 99.7$ million as compared to $\$ 102.79$ million by taking into account the uncertainty in the cost item but without considering any risk factors. On the other hand, maximum cost with risk factors can be seen as $\$ 125.09$ which is around $25 \%$ more than the company's base cost.

The total estimated cost for this project is $\$ 121.02$ (Table 3) million with contingencies and all other factors. Based on Fig. 2 we can say that there is $8 \%$ chance that the cost will exceed the total estimated budget. Figure 3 presents the frequency distribution chart for cost with risk factors being incorporated. The expected project cost (mean) and standard deviation are \$117.43 and \$3.3 million, respectively. This shows that the increase in cost due to the risks leading to extended project duration is not accurately predicted.

Further, the model sensitivity analysis helps identify that the major risks impacting the project's cost were limited to three factors, which are listed below with their ranking:

1. Late placement of purchase orders (43.8\%)

2. Unauthorized deviation from vendor leading to rework and schedule delay (28.2\%).

3. Late provision of vendor data resulting in a delay of the AFC package (27.9\%).

For risks 1 and 2, the impact of their occurrence is very significant and will lead to a cost increase of about $\$ 10$ million (associated with the re-work and schedule delay). For risk 3, the cost impact is not significant (about $\$ 1$ million). However, the impact on schedule of this risk is huge (3 months' delay in detailed design). The cost associated with this activity will vary depending on man-hours necessary to carry out the activity.

Concerning the other 13 risk factors, their impact is negligible compared to the identified major risks. A sensitivity analysis has also been carried out assuming that these three risks have been mitigated and closed. This has resulted in risk No. 5, i.e., complex interfaces between the different vendors, being the most critical risk with severe impact on cost.

\section{Project duration}

The results from the model runs related to the project duration are summarized in Table 8 . The table summarizes the results of predicted on stream date and compares it with the base case scenario.

The base schedule without considering any risks and with the assumption that activity distribution is uniform is estimated to take total duration of 782 days and finish by 9 th November 2013. Since the distribution of each activity has been defined as triangular distribution, with most likely, optimistic and pessimistic durations, the model has predicted the different scenarios of completion based on the defined distributions.

The promised on stream date to management is October 2013. However, as shown in Fig. 4, the model has predicted $0 \%$ chance that the project can be completed before April 2014 if we take risk factor into account. Figure 5 indicates that there is only $55 \%$ chance that the project will finish before Feb 03, 2015.

Similar to cost analysis, further, model sensitivity analysis helps identify major risks affecting the project's duration, which are listed as below with their ranking: 
Table 6 Result obtained from the probabilistic model

\begin{tabular}{lll}
\hline Risk & Risk level \\
\hline Unauthorized deviation from vendor & High & Ranking \\
Late provision of vendor data & High & Medium \\
Late placement of the purchase orders & High \\
Late arrival of materials on site due to poor vendor performance or quality failures & High \\
Complex interfaces within package vendors & High \\
Lack of installation and commissioning spares & High \\
Failure during acceptance testing & High \\
Inexperience of construction contractor on CRA material & High \\
Construction productivity is poor due to concurrent operations and $\mathrm{H}_{2} \mathrm{~S}$ safety & High \\
Delay in receiving pipe and pipe fittings & Medium \\
Failure of vendors to comply with approved designs & Medium \\
Footprint specified in the plot plan is not met by the package vendors & High \\
Lack of sound experience of E\&P contractor & High \\
Lack of adequate operations staff & High \\
Market price rise & High \\
Working adjacent to existing live plant leading to exposure to high $\mathrm{H}_{2} \mathrm{~S}$ gas & 0.2 \\
\hline
\end{tabular}

Table 7 Cost comparison (all costs are in million \$)

\begin{tabular}{|c|c|c|c|c|c|c|c|}
\hline \multicolumn{2}{|c|}{ Company cost estimate } & \multicolumn{3}{|c|}{ Without risks } & \multicolumn{3}{|c|}{ With risks } \\
\hline Base cost & Total estimated cost & Low & Base & High & Low & Base & High \\
\hline 99.7 & 121.02 & 98.74 & 102.79 & 107.04 & 102.25 & 117.43 & 125.09 \\
\hline- & $21 \%$ & $-1 \%$ & $3 \%$ & $7 \%$ & $3 \%$ & $18 \%$ & $25 \%$ \\
\hline
\end{tabular}

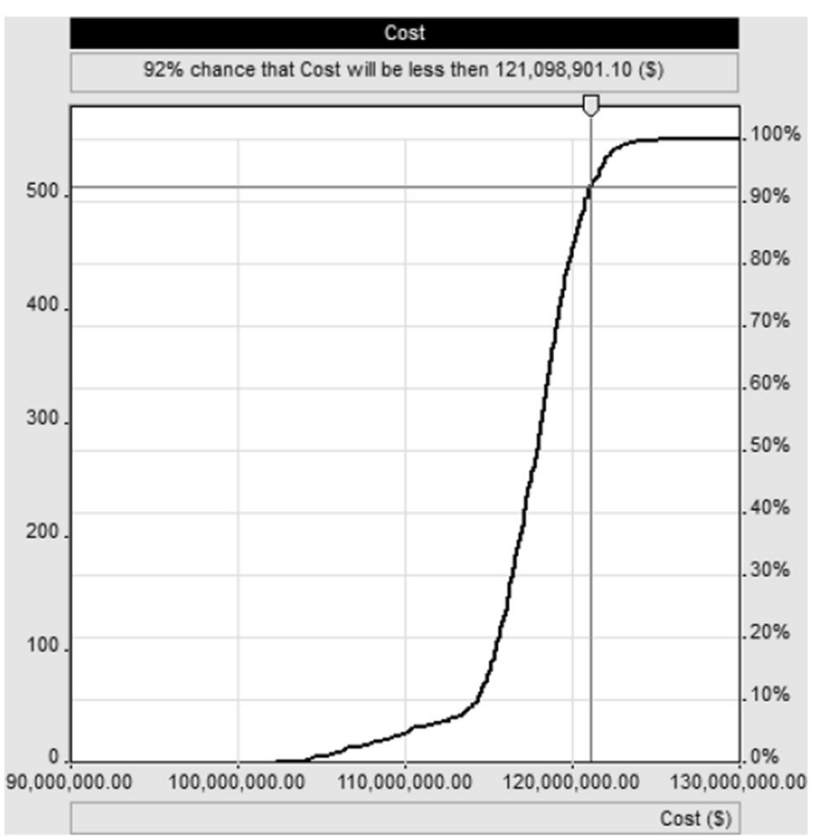

Fig. 2 Cost cumulative probability chart

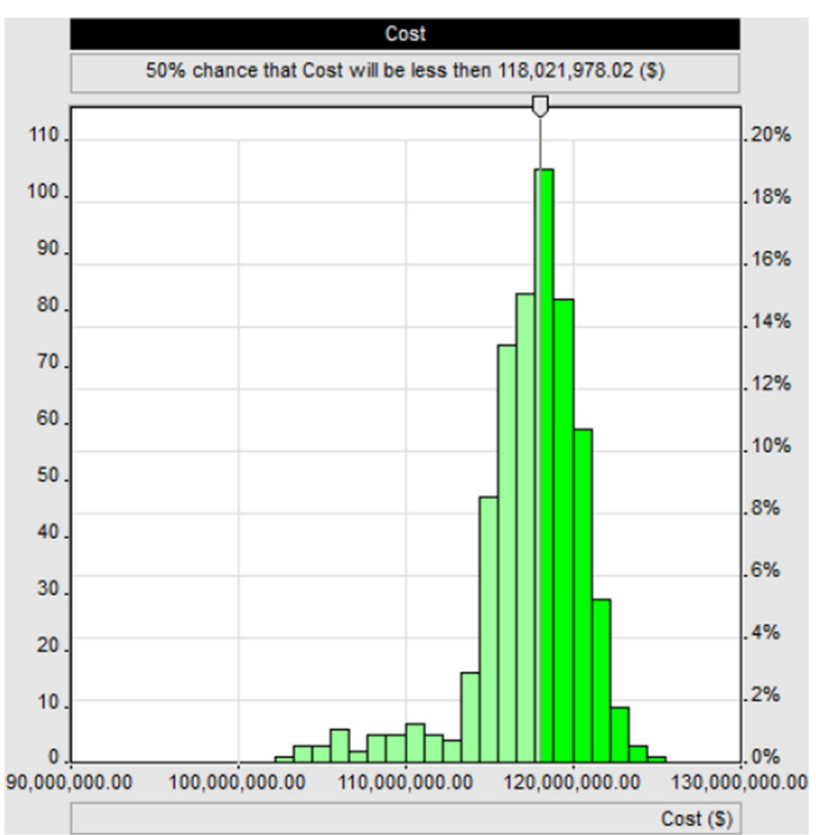

Fig. 3 Cost frequency distribution chart (with Risks) 
1. Unauthorized deviation from vendor leading to rework and schedule delay (39.9\%).

2. Late provision of vendor data resulting in a delay of the AFC package (24.3\%).

3. Late arrival of materials on site due to poor vendor performance and quality failure $(10.6 \%)$.

4. Complex interfaces within package vendors $(10.1 \%)$.

5. Lack of installation and commissioning spares leading to delays $(7.9 \%)$.

6. Failure during acceptance tests (factory and site) resulting in delays $(7.1 \%)$.

Risks 1, 2 and 4 are causing delay in detailed design activities. For example, risk 4 is the result of having number of vendors working in different interfaces. Historically, this risk has caused severe delays in past projects. Risks 3, 5 and 6 are related to construction and commissioning activities.

Concerning the other ten risk factors, their impact is negligible compared to the identified major risks. A sensitivity analysis has been carried out further assuming that these six risks have been mitigated and closed. It was found that failure of vendors to comply with approved designs $(48.9 \%)$ is the most critical risk. This risk will have a severe impact on duration. This is followed by the late placement of PO (34.8\%) and then by the lack of operation staff (16.3\%).

The impact of increased cost and duration has also been checked on the Net Present Value of the project using economical spreadsheet. The incremental oil production introduced due to commencing of this project is expected to be in an average of 2500 barrels per day. The NPV calculation was performed for two cases. Case one with the original cost and target on stream date. Case two with results achieved from the high-risk run with a delay of more than 2 years and probability of increase in total cost by $8 \%$. Operating cost has been ignored and same oil price, discount rate, and field life have been considered for both cases. The reduction in Net Present Value (NPV) with the increased cost and delayed onstream date is estimated to be $72 \%$.

\section{Managerial implications}

Projects are associated with the constraint of cost and schedule and no project is free of risks. Project involves many tasks which have to be carried out within their own timeframe and budget limit. Any unforeseen situation in the task will make it differ it from estimated cost and schedule. This consequently results in the cost overrun and delay of the whole project as one task will be connected with others. Following major insights for project manager can be drawn from the study:

- To avoid project failure, associated risks have to be managed properly. The project manager should not treat project schedule, cost estimation and risk register as separate, isolated systems. In addition to the identified risk factors, uncertainties in activity duration and cost estimates must be considered when they occur.

- Project managers are interested in knowing the probability of achieving promised targets and the risks they should "keep an eye on". Deterministic analysis or qualitative analysis can predict that a project will not meet its target milestone but it will not predict how far it is from achieving them. Such prediction is possible by using simulation through quantitative analysis.

- Monte Carlo simulation as a tool to perform risk analysis can be very beneficial to assist in successfully completing the projects and companies should consider implementing it. It helps in determining the required contingency to be added into the cost estimate and the float needed in the plan. Further, it gives ranges of the possible project cost and duration instead of a single deterministic value. This will help in planning the resources efficiently, thereby giving the management team realistic projections.

- Simulation result can aid the project team in developing the mitigation plan to prioritize their efforts to focus on those risks that will have maximum effect on the project. Consequently, instead of investing in mitigation of the all risk factors, the project team can consider those which would drive the project to exceed its budget and duration drastically.

\section{Conclusions and recommendations}

To avoid project failure, it is necessary to manage the associated risks properly. It has been found that most of the companies treat project schedule and cost estimate as an isolated system. In addition, company fails to incorporate risks associated with duration and cost estimate of various activities involved in the project. Therefore, to overcome
Table 8 Completion date scenarios

\begin{tabular}{|c|c|c|c|c|c|c|c|}
\hline & \multirow[t]{2}{*}{ Company target } & \multicolumn{3}{|c|}{ Without risks } & \multicolumn{3}{|c|}{ With risks } \\
\hline & & Low & Base & High & Low & Base & High \\
\hline Duration (days) & 782 & 783.7 & 828 & 881 & 882 & 1041 & 1279 \\
\hline \multirow[t]{2}{*}{ On stream date } & $9 / 11 / 13$ & $10 / 11 / 13$ & $26 / 1 / 14$ & $29 / 4 / 14$ & $1 / 5 / 14$ & $3 / 2 / 15$ & $27 / 3 / 16$ \\
\hline & - & $0.2 \%$ & $6 \%$ & $13 \%$ & $13 \%$ & $33 \%$ & $64 \%$ \\
\hline
\end{tabular}


Fig. 4 Frequency distribution chart for project's on-stream date (with Risks)

Fig. 5 Cumulative probability chart for project's on-stream date (with Risks)
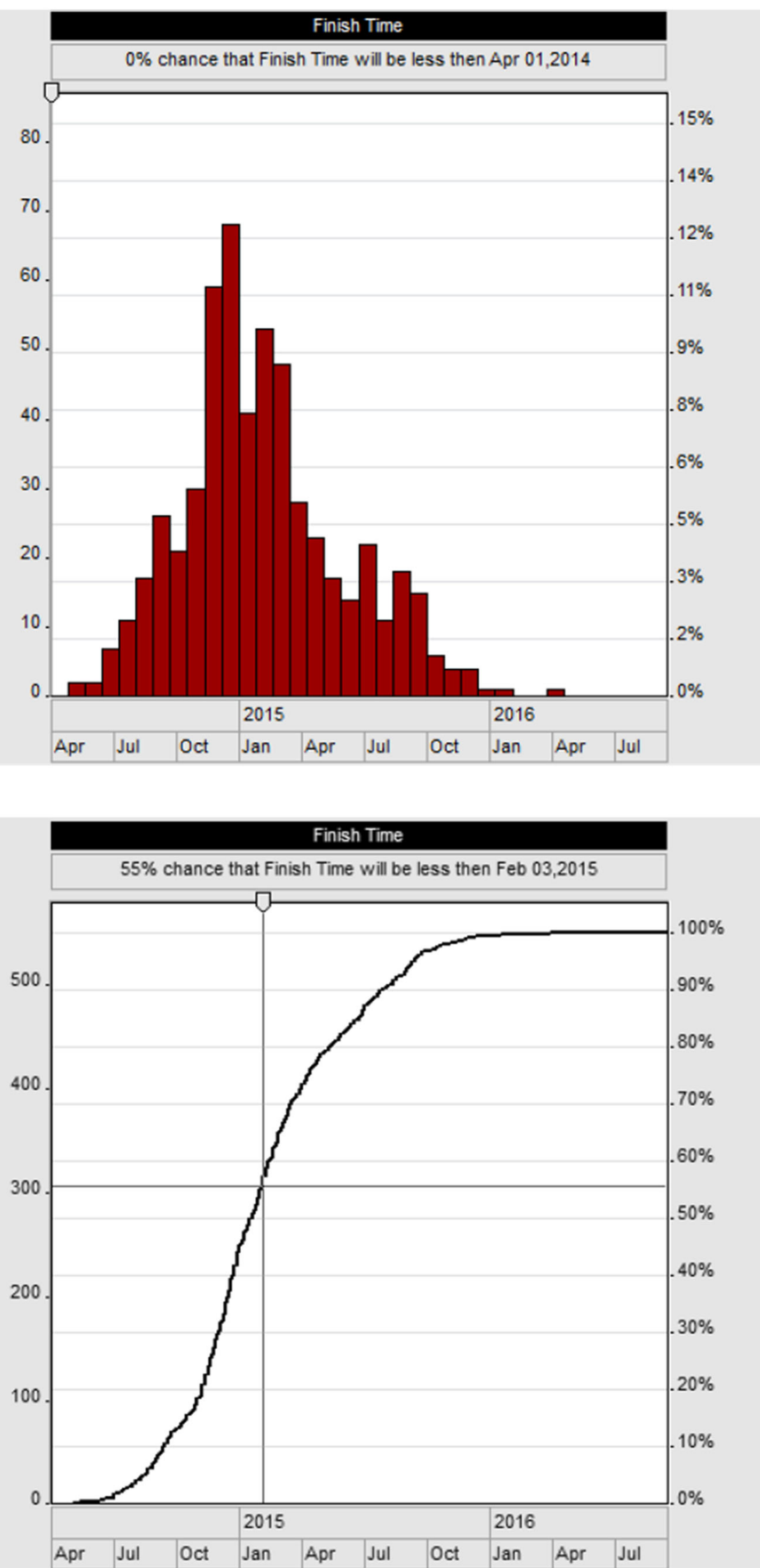
these issues, in this paper we study the management of risks in an oil and gas project being implemented by a company in Oman. The paper proposed the use of stochastic model by integrating schedule and cost estimate to perform risk analysis in such project.

In the paper, Monte Carlo simulation is used as a tool to conduct numerical analysis using RiskyProject Professional $^{\mathrm{TM}}$ software. The simulation result predicted a delay of about 2 years as a worse case with no chance of meeting the project's on stream date. Also, it has predicted $8 \%$ chance of exceeding the total estimated budget. The result of numerical analysis from the proposed model is validated by comparing it with the result of qualitative analysis, which was obtained through discussion with various project managers of company.

Along with predicting delay in project schedule and inaccuracy in cost estimation, the developed model can also be used to predict most critical risks that would impact on the project. Such information can aid the project team in re-developing mitigation plan to prioritize their efforts on those risks that got highest impact on project's objectives.

At present, the research has considered only projects on stream date and cost estimate as issues in an effort on mitigating the risk. However, apart from these issues, safety and performance are of critical issues in oil and gas industry. Therefore, research can be extended to incorporate these issues in the project objectives.

Open Access This article is distributed under the terms of the Creative Commons Attribution 4.0 International License (http://crea tivecommons.org/licenses/by/4.0/), which permits unrestricted use, distribution, and reproduction in any medium, provided you give appropriate credit to the original author(s) and the source, provide a link to the Creative Commons license, and indicate if changes were made.

\section{Appendix 1}

See Tables 9 and 10.
Table 9 Cost breakdown for modeling input data

\begin{tabular}{|c|c|c|c|}
\hline Cost item & Fixed & Variable & Total, \$ \\
\hline \multicolumn{4}{|l|}{ Engineering } \\
\hline FEED & $4,092,113$ & & $4,092,113$ \\
\hline DD & 2,314 & $7,677,686$ & $7,680,000$ \\
\hline \multicolumn{4}{|l|}{ Procurement } \\
\hline Mechanical/main equipment & $31,925,500$ & $5,302,606$ & $37,228,106$ \\
\hline Injection compressor & $5,767,433$ & 757,515 & $6,524,948$ \\
\hline TEG unit & $1,323,973$ & $1,093,123$ & $2,417,096$ \\
\hline Instrument air & $1,494,652$ & 335,608 & $1,830,260$ \\
\hline CRA valves & 249,064 & 407,524 & 656,588 \\
\hline ESD valves & 368,924 & 287,664 & 656,588 \\
\hline Flow control valve & $2,505,961$ & 287,664 & $2,793,625$ \\
\hline Barred tee and welded isolation valves & $2,529,933$ & 263,692 & $2,793,625$ \\
\hline Wellpad piping material & $2,553,905$ & 239,720 & $2,793,625$ \\
\hline Wellpad valves & $2,529,933$ & 263,692 & $2,793,625$ \\
\hline Wellhead hydraulic control panel & $2,553,905$ & 239,720 & $2,793,625$ \\
\hline $70 \%$ Bulk & $2,553,905$ & 239,720 & $2,793,625$ \\
\hline Final bulk & $2,553,905$ & 239,720 & $2,793,625$ \\
\hline Bulk material on-plot & $2,553,905$ & 239,720 & $2,793,625$ \\
\hline $90 \%$ Bulk material on-plot & $2,386,101$ & 407,524 & $2,793,625$ \\
\hline Piping/pipeline & $4,696,701$ & 671,216 & $5,367,917$ \\
\hline Pipeline & $3,458,681$ & 263,692 & $3,722,373$ \\
\hline Piping & $1,238,020$ & 407,524 & $1,645,544$ \\
\hline Electrical & $11,941,828$ & 407,524 & $12,349,352$ \\
\hline Instrumentation & $4,276,143$ & 263,692 & $4,539,835$ \\
\hline \multicolumn{4}{|l|}{ Construction } \\
\hline On plot construction & $5,792,312$ & & $5,792,312$ \\
\hline Off plot construction & $22,432,712$ & & $22,432,712$ \\
\hline Commission and start up & 247,474 & & 247,474 \\
\hline Total & $85,407,096$ & $14,322,724$ & $99,729,820$ \\
\hline
\end{tabular}




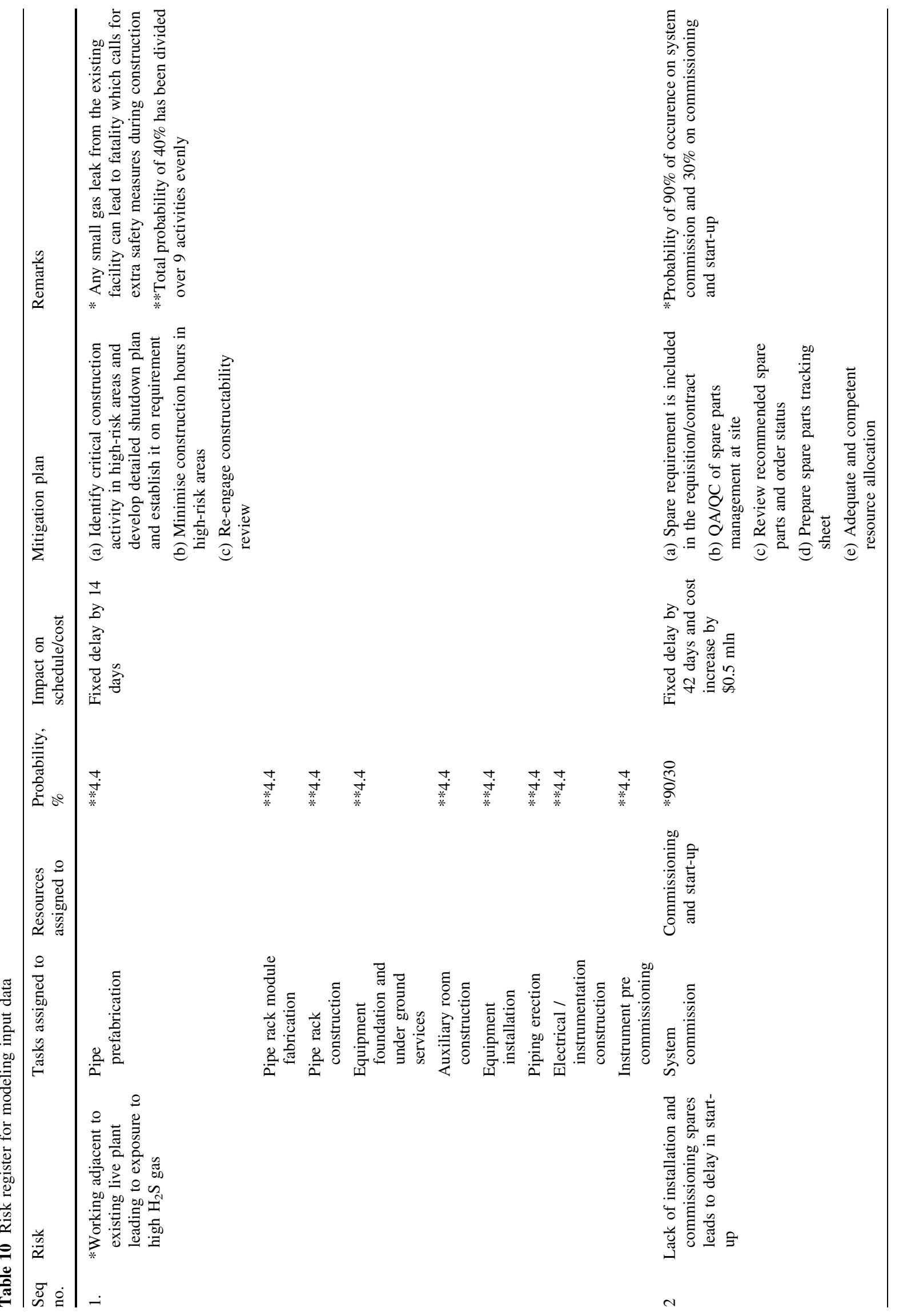




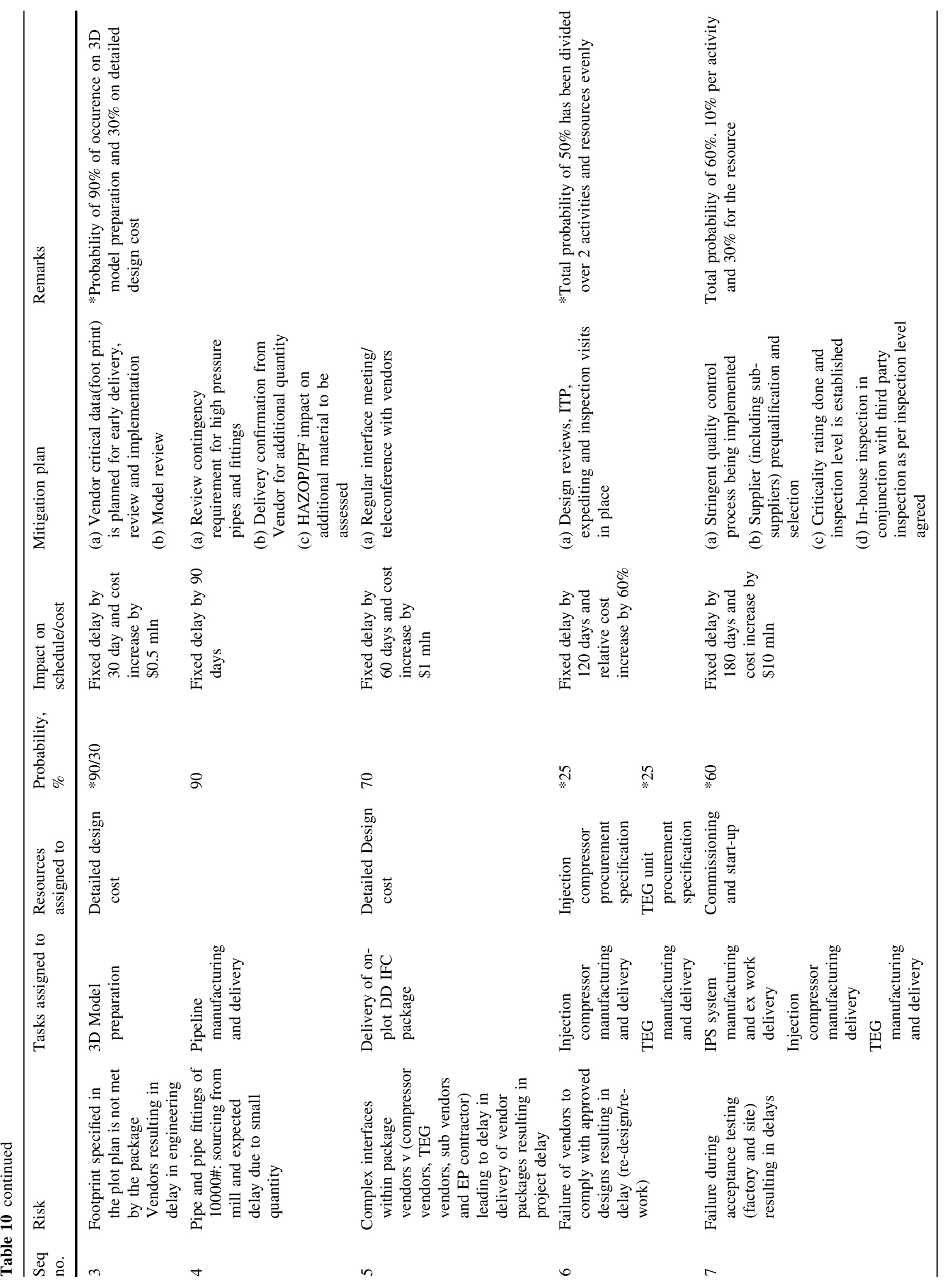




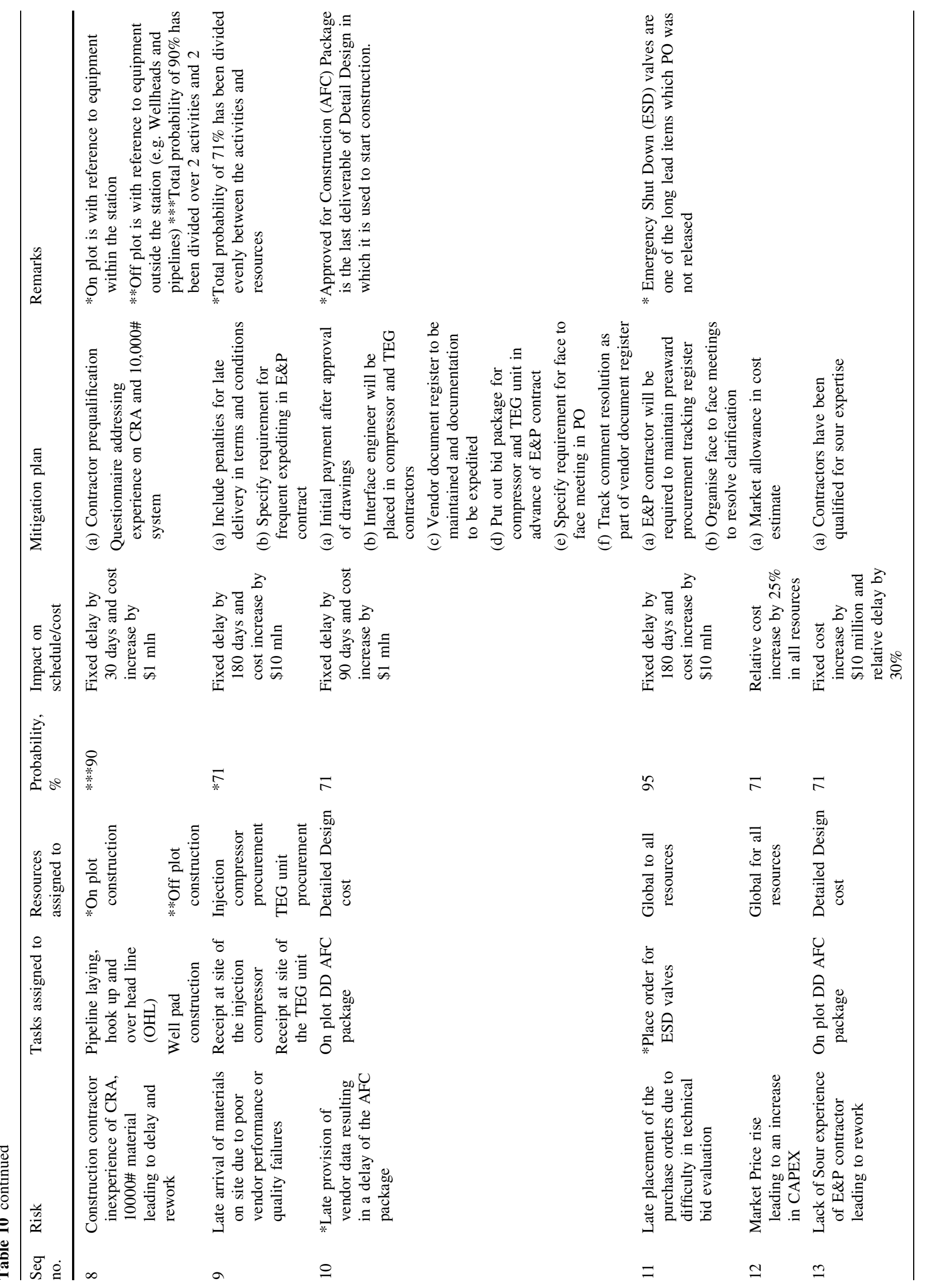




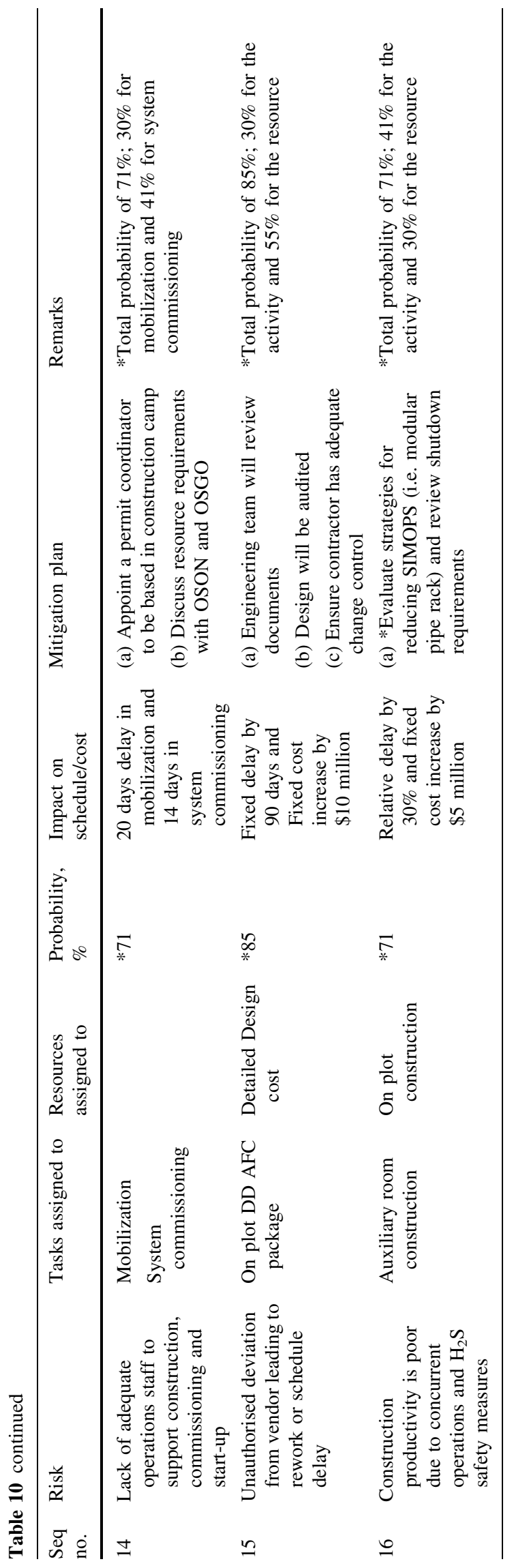

\section{References}

Aggarwal P, Ganeshan R (2007) Using risk-management tools on B2Bs: an exploratory investigation. Int $\mathrm{J}$ Prod Econ 108(1-2):2-7

Alhawari S, Karadsheh L, Talet AN, Mansour E (2012) Knowledgebased risk management framework for information technology project. Int J Inf Manag 32(1):50-65

Aqlan F, Lam SS (2015) A fuzzy-based integrated framework for supply chain risk assessment. Int J Prod Econ 161:455-470

Artto K, Eloranta K, Kujala J (2008) Subcontractors' business relationships as risk sources in project networks. Int $\mathbf{J}$ Manag Proj Bus 1(1):88-105

Aven T, Vinnem JE (2005) On the use of risk acceptance criteria in the offshore oil and gas industry. Reliab Eng Syst Saf 90(1):15-24

Balasubramanian V, Narendran TT, Sai Praveen V (2011) RBG risk scale: an integrated tool for ergonomic risk assessments. Int J Ind Syst Eng 8(1):104-116

Bosch-Rekveldt M, Jongkind Y, Mooi H, Bakker H, Verbraeck A (2011) Grasping project complexity in large engineering projects: the TOE (technical, organizational and environment) framework. Int J Proj Manag 29(6):728-739

Bourne L, Walker DHT (2008) Project relationship management and the Stakeholder Circle. Int J Manag Proj Bus 1(1):125-130

Chapman CB, Ward S (2002) Managing project risk and uncertainty: a constructively simple approach to decision making. Wiley, New York

Chapman CB, Ward S (2003) Project risk management: processes, techniques and insights, 2nd edn. Wiley, New York

Chou J (2011) Cost simulation in an item based project involving construction engineering and management. Int $\mathbf{J}$ Proj Manag 29(6):706-717

Esmaeili M, Bahrini A, Shayanrad S (2015) Using game theory approach to interpret stable policies for Iran's oil and gas common resources conflicts with Iraq and Qatar. J Ind Eng Int 11(4):543-554

Fan M, Lin N, Sheu C (2008) Choosing a project risk-handling strategy: an analytical model. Int J Prod Econ 112(2):700-713

Giannakis M, Papadopoulos T (2016) Supply chain sustainability: a risk management approach. Int J Prod Econ 171(4):455-470

Giannkis M, Louis M (2011) A multi-agent based framework for supply chain risk management. J Purch Suppl Manag 17(1):23-31

Ika LA, Diallo A, Thuillier D (2010) Project management in the international development industry: the project coordinator's perspective. Int J Manag Proj Bus 3(1):61-93

Jaafari A (2001) Managing risks, uncertainties and opportunities on projects: time for a fundamental shift. Int $\mathrm{J}$ Proj Manag 19(2):89-101

Javani B, Rwelamila PMD (2016) Risk management in IT projects-a case of the South African public sector. Int J Manag Proj Bus 9(2):389-413

Jouandou R (2009) Dealing with uncertainty: selecting a risk analysis tool on the basis of project characteristics and phases. Master thesis, University of Colorado, viewed 24 May 2016, ProQuest, http://ezproxy.squ.edu.om:2062/docview/847553742

Khalaj M, Khalaj F, Khalaj A (2013) A novel risk-based analysis for the production system under epistemic uncertainty. J Ind Eng Int 9(1):1-10

Kirchsteiger C (1999) On the use of probabilistic and deterministic methods in risk analysis. J Loss Prev Process Ind 12(5):399-419

Kirkire MS, Rane SB, Jadhav JR (2015) Risk management in medical product development process using traditional FMEA and fuzzy linguistic approach: a case study. J Ind Eng Int 11(4):595-611 
Komlosi Z (2001) Application: Monte Carlo simulation in risk evaluation of E\&P projects. In: SPE Hydrocarbon Economics and Evaluation Symposium, Dallas, Texas, 2-3 April

Lewis TL (2010) Quantitative approach to technical performance measurement and technical risk analysis utilizing Bayesian methods and Monte Carlo simulation. (Doctoral dissertation, The George Washington University)

Lewis D, Guerrero V, Saeed S, Marcon MF, Hyden R (2004) The relationship between petroleum economics and risk analysis: a new integrated approach for project management. In: SPE/IADC Underbalanced Technology Conference and Exhibition. Society of Petroleum Engineers

Mahmood WHW, Rahman MNA, Deros BM, Mazli H (2011) Maintenance management system for upstream operations in oil and gas industry: a case study. Int J Ind Syst Eng 9(3):317-329

Marcelino-Sadaba S, Perez-Ezcurdia A, Lazcano AME, Villanueva P (2014) Project risk management methodology for small firms. Int J Proj Manag 32(2):327-340

Miller KD (1990) Strategic risk and corporate performance: an analysis of alternative risk measures. Acad Manag J 33(4):756-779

Miller KD (1992) A framework for integrated risk management in international business. J Int Bus Stud 23(2):311-331

Miller KD, Waller HG (2003) Scenarios, real options and integrated risk management. Long Range Plan 36(1):93-107

Narasimhan R, Talluri S (2009) Perspectives on risk management in supply chains. J Oper Manag 27(2):114-118

Palisade (2016) Available on http://www.palisade.com/risk/risk_ analysis.asp. Accessed on 24th May 2016

Patterson F, Neailey K (2002) A risk register database system to aid the management of project risk. Int J Proj Manag 20(5):365-374

Perminova O, Gustafsson M, Wikstrom K (2008) Defining uncertainty in projects-a new perspective. Int $\mathrm{J}$ Proj Manag 26(1):73-79

Pettit TJ, Fiksel J, Croxton KL (2010) Ensuring supply chain resilience: development of a conceptual framework. J Bus Logist 31(1):1-21

Pinsonneault A, Kraemer K (1993) Survey research methodology in management information systems: an assessment. J Manag Inf Syst 10(2):75-105

PMI Standards Committee and PMI Standards Committee (1996) A guide to the project management body of knowledge. Project Management Institute
Ramos SB, Veiga H (2011) Risk factors in oil and gas industry returns: international evidens. Energy Econ 33(3):525-542

Raz T, Michael E (2001) Use and benefits of tools for project risk management. Int J Proj Manag 19(1):9-17

Selvik JT, Aven T (2011) A framework for reliability and risk centered maintenance. Reliab Eng Syst Saf 96(2):324-331

Smith K (2009) Environmental hazards: assessing risk and reducing disaster, 5th edn. Routledge Publisher, Oxon

Suslick SB, Schiozer DJ (2004) Risk analysis applied to petroleum exploration and production: an overview. J Petrol Sci Eng 44(1-2):1-9

Tah JHM, Carr V (2001) Towards a framework for project risk knowledge management in the construction supply chain. Adv Eng Softw 32(10-11):835-846

Trkman P, McCormack K (2009) Supply chain risk in turbulent environments-a conceptual model for managing supply chain network risk. Int J Prod Econ 119(2):247-258

Vose D (2008) Risk analysis: a quantitative guide. Wiley, Westy Sussex

Wang SQ, Dulaimi MF, Aguria MY (2004) Risk management framework for construction projects in developing countries. Constr Manag Econ 22:237-252

Wang J, Lin W, Huang Y-H (2010) A performance-oriented risk management framework for innovative R\&D projects. Technovation 30(11-12):601-611

Ward S, Chapman C (2003) Transforming project risk management into project uncertainty management. Int $\mathrm{J}$ Proj Manag 21(2):97-105

Westney R (2001) Managing the cost \& schedule risk of offshore development projects. In: Paper presented at the 2001 Offshore Technology Conference, Houston, Texas, 30 April-3 May

Yildiz AE, Dikmen I, Birgonul MT, Ercoskun K, Alten S (2014) A knowledge-based risk mapping tool for cost estimation of international construction projects. Autom Constr 43:144-155

Zhang X, Wuwong N, Li H, Zhang X (2010) Information security risk management framework for the cloud computing environments. In: IEEE 10th International Conference on Computer and Information Technology June 29-July 1, Bradford, UK, pp. $1328-1334$ 